\title{
An E-Activities Platform to Support SMEs
}

\author{
Athanasios Drigas', Leyteris Koukianakis ${ }^{1}$, and Yannis Papagerasimou ${ }^{1}$ \\ 1 Applied Technologies Department, NCSR "DEMOKRITOS" \\ Ag. Paraskevi, 153 10, Athens, Greece \\ \{dr, kouk, ypapa\}@imm.demokritos.gr \\ WWW home page: http://imm.demokritos.gr
}

\begin{abstract}
E-activities are considered a very powerful tool for the strengthening of enterprises and enterprising in general. They include among others, e-learning, e-government, e-commerce and e-business, which are the main e-activities that directly interest the enterprises. This article presents and describes a compound e-government environment-application that is addressed to enterprises, which incorporates e-learning and training activities within the enterprises on issues covering ICTs and e-activities. Moreover, particular emphasis is given to the exploitation of the Internet technologies and ecommerce from the enterprises in order to exploit the various forms of ecommerce and e-promotion of their products. For example through B2B transactions (Business to Business), there is the potential of reducing the operational expenses for the procurement cycle for their products. Furthermore, through B2C transactions (Business to Consumer), there is the potential to promote worldwide the products and services of the SMEs and finally, through e-advertisement there is the opportunity to exploit the Internet as a promotion medium for the activities of the SMEs. The environment covers all the aforementioned e-services and offers educational e-content for them. Finally, this article presents the electronic infrastructure that was developed in the framework of a relevant European project (Leonardo $\mathrm{Da} V$ inci) for the supporting of e-activities in the field of enterprising and SMEs.
\end{abstract}

\section{Introduction}

The issues for governments are to foster appropriate business environments for ebusiness and ICT uptake (e.g. to diffuse broadband, enhance competition), and target program to overcome market failures to the extent that they are needed in particular areas (e.g. skill formation, specialized information) [1].

More and more governments are using information and communication technologies and especially the Internet or web-based applications, to provide

Please use the following format when citing this chapter:

Drigas, A., Koukianakis, L., Papagcrasimou, Y., 2006, in International Fedcration for Information Processing, Volume 205, Research and Practical Issues of Enterprise Information Systems, eds. Tjoa, A.M., Xu, L., Chaudhry, S., (Boston:Springer), pp.467-477. 
services among governmental agencies and citizens, businesses, employees and other non-governmental organizations [2 - 5].

On the other hand, Information and Communication Technologies (ICTs) and ebusiness applications provide many benefits across a wide range of intra- and interfirm business processes and transactions. ICT applications improve information and knowledge management inside the firm and can reduce transaction costs and at the same time increase the speed and reliability of transactions for both business-tobusiness (B2B) and business-to-consumer (B2C) transactions. In addition, they are effective tools for improving external communications and quality of service for established and new customers [6 - 8].

Furthermore e-learning and e-services are the Internet sectors which have a continuously increasing growth rate. The business community is the community which has taken advantage of e-learning services the most, mainly for staff training reducing hence, the training cost. In addition, the business community has taken advantage of e-commerce (B2C) to penetrate the global market and of e-commerce (B2E) to handle and improve employees' management, e-advertisement and to promote the companies' products and services [9 - 14].

The way such organizations cultivate learning and how they retain knowledge is fundamental to the success of organizations in the knowledge economy. E-learning can aid an organization to develop its knowledge base [15, 16]. E-learning is instructional content or learning experience delivered or enabled by electronic technologies. For e-learning to become a core part of the training strategy of organizations, the latter need to be clear of the business benefits it delivers [17-22].

There is no doubt of the e-learning industry's aggressive growth, nowadays. Enlightened executives are not considering e-learning an isolated activity, but rather, a piece of the overall business strategy. Hewlett-Packard's learning portal, @hp, handles HR, administrative and training functions for more than 90,000 employees around the world. Course offerings range from IT courses to leadership development courses. The greatest business benefits to be documented are a significant reduction in paperwork and faster decision-making by employees [23]. However, research indicates that instructor-led training is still the most popular and most used training method within organisations $[13,24]$.

\section{System Analysis}

\subsection{3-tier Architecture}

The environment's modularity and flexibility are based on the widely adopted 3-tier model. This architecture ensures the effective management of resources, the best data range, and security. The architecture includes the following tiers: presentation, application and data management. The middle or application tier is responsible for the presentation of data to the users while the third or data management tier deals with the management of the database transactions. Moreover, the middle tier limits the user access to secure data, enforcing the system security. 


\subsection{Environment Tools}

The environment includes tools that offer flexibility and adaptability depending on their use. The design of these tools was based on the existing web services, such as discussion forums [25], chat, message box, e-libraries [26], which are widespread in the public web community. These tools are distinguished into two groups: "informative" and "communicative". On the one hand, the "informative" tools include services related to the educational material and its presentation. On the other hand, the "communicative" tools include services that allow the communication of different user groups (users belonging to a different session level).

The environment offers the possibility of management of these tools according to the user groups' permission. More explicitly, the "informative" tools include the following: list of courses, list of educational material, examples, exercises, multiple choices, glossary, references, web Links, e-library, announcements. Respectively, the "communicative" tools include: discussion forums and message boxes, video and audio conferences and chat. Finally, it must be noted that the environment relates the tools to the educational material courses according to the specific user level permissions. These levels are analyzed in the sections to follow.

\subsection{User Levels}

Four user levels are distinguished (Fig. 1) in the environment. In each of them different supporting tools exist. Depending on the corresponding use, these levels have also a different role: administrator, instructor, student and unauthorized user. Each of them interacts with the other through the "informative" and "communicative"' tools related to each level. 


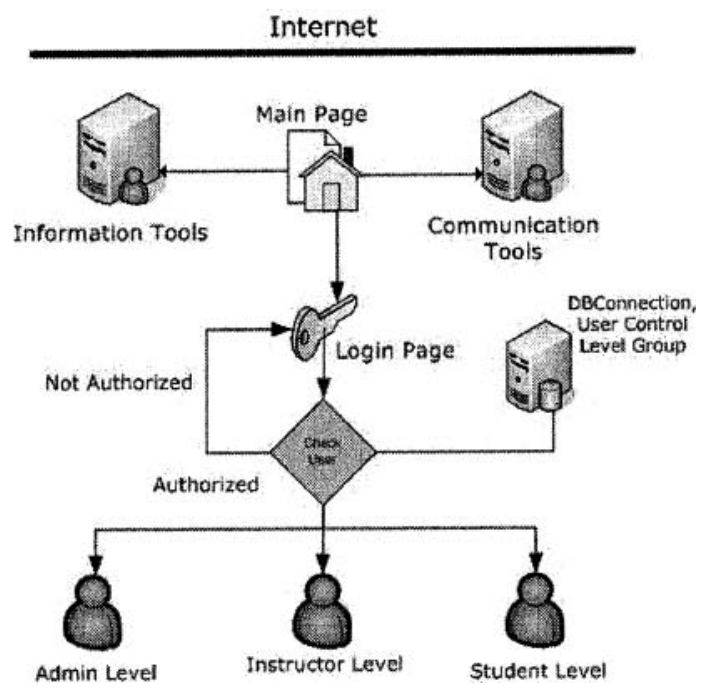

Fig. 1. The user-level diagram

\section{User Tools and Services}

\subsection{Administration Tools}

The environment provides administrative e-services and e-activities that are separated in three groups as follows: management of general services, of "informative" services and of "communicative" services (Fig. 2). The transactions executed in each group concern the retrieval, insertion and update of the corresponding data. More explicitly, the "general services" group of e-services and e-activities includes management of the data structures of: news, events, announcements and the user. The management of the "informative" e-services and e-activities is of major importance, as it enables the administrator to determine the type and number of seminars, classes, courses, instructors and students.

The "communicative services" group includes services through which the administrator can manage: announcements, the e-library of courses and the discussion forums between instructors and students. Moreover, through certain services the administrator communicates with each of the instructors separately. 


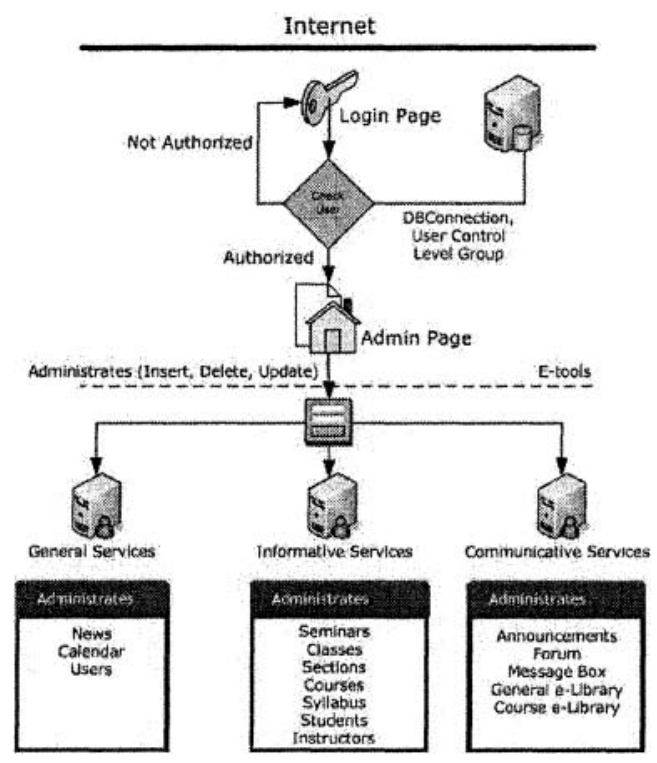

Fig. 2. Administrator Level Diagram

\subsection{Instructor's Tools}

The tools and e-services help the instructor to organize the course in a way that will help the students-employees in the direct comprehension of the course. The instructor can manage the courses' accompanying material (Fig. 3). Finally the tools and e-services enable the instructor to perceive the learning weaknesses of his/her students, and to select the education process of each course. More explicitly, the instructor's tools and e-services can be separated into three groups as follows: general e-services that include management tools of news, events, profile, courses retrieval/search, syllabus and educational material. The second group includes tools and e-services that allow the fast access to the consulting material, which includes: examples, exercises, multiple choices, glossary, references, web links, e-library, announcements, solutions of exercises, discussions between students and instructors.

The third and more basic group of the instructors' tools and e-services is the one that enables the instructor to build and manage the educational material of his courses: the educational material (chapters, sub-chapters, paragraphs), the accompanying material (examples, exercises, multiple choice, glossary, references, web links, e-library, announcements), the discussions between his/her students on the answers of questions, the discussions with his/her students on the practical application of the educational subjects and finally, his/her message box from the personal communication with the administrator. 


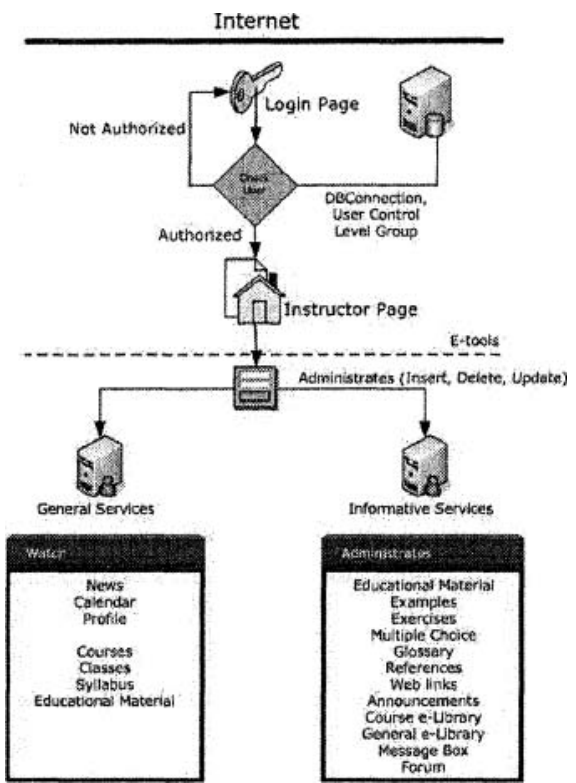

Fig. 3. Instructor Level Diagram

\subsection{Student Tools}

Through a user friendly and direct way, the environment enables the studentemployee, via the usage of a set of e-services and e-activities, to have access to the total amount of the educational material with final aim, the acquisition of knowledge (Fig. 4).

The students' tools and e-services can be separated into two groups as follows: general e-services that allow the fast access to: news, events, courses, syllabus, and to educational material. The second group includes tools and e-services that allow the fast access to the consulting material: examples, exercises, solutions of exercises, multiple choices, glossary, references, web links, and e-library. What is important in this group is the possibility of communication with the instructor via the discussion forums. 


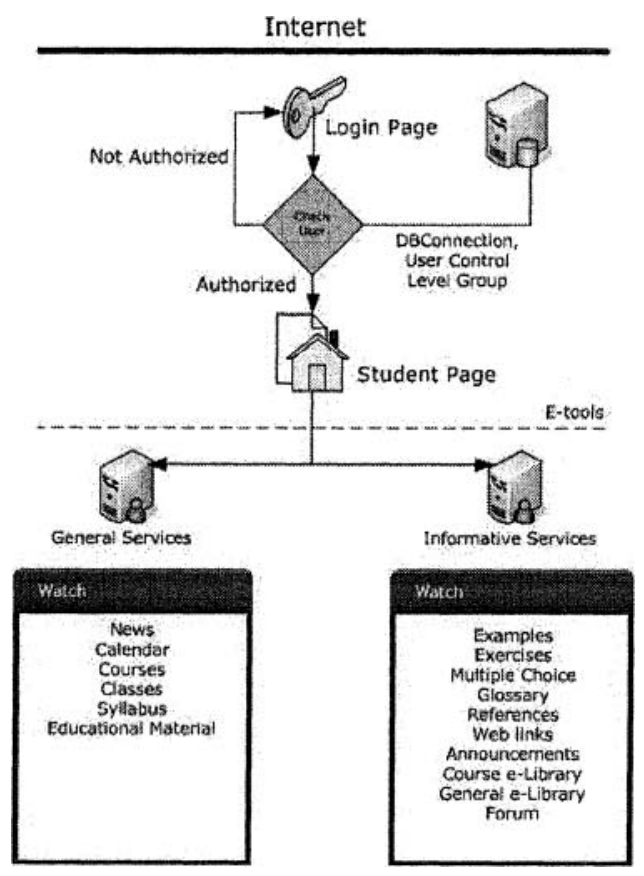

Fig. 4. Student Level Diagram

Moreover, the student-employee has access to the answers of his/her questions but also discusses with the instructor the practical application of the theoretical subjects. Finally, the environment aims at the biggest possible parallelism of education in the traditional classroom, with the education in a virtual classroom.

\section{Importance of E-Services and E-Learning in SMEs}

The importance of e-services and training via e-learning methods to company competitiveness and employee motivation has been highlighted by many researchers $[27,28]$. Some of the most outstanding advantages are:

To the company:

- Flexibility in responding to contextual changes

- Timeliness of adaptation to normative and contractual purviews

- Labour and organisational quality

- Resource optimization

- Maximization of profitability

- Greater competitiveness 
To the employees:

- Capitalization and certification of the worker's own competencies

- Acquisition of new competencies

- Transferability of new competencies

- Increased value of the worker's own role

- Greater personal motivation

- Greater knowledge of the worker's own role

Furthermore, e-learning promises to provide a unique experience that accommodates the three distinct learning styles of auditory learners, visual learners and kinaesthetic learners. E-learning also offers individualized instruction, which print media cannot provide, and which instructor led courses allow clumsily and at great cost.

Some of the most outstanding advantages to the trainer or organization are:

- Reduced overall cost is the single most influential factor in adopting elearning. The elimination of costs associated with instructors' salaries, meeting room rentals, and student travel, lodging, and meals are directly quantifiable. The reduction of time spent away from the job by employees may be the most positive offshoot.

- Learning times reduced, an average of 40 to 60 percent

- Increased retention and application to the job averages an increase of 25 percent over traditional methods,

- Consistent delivery of content is possible with asynchronous, self-paced e-learning.

- Expert knowledge is communicated, but more importantly captured, with good e-learning and knowledge management systems.

- Proof of completion and certification, which essential elements of training initiatives, can be automated.

Along with the increased retention, reduced learning time, and other aforementioned benefits to students, particular advantages of e-learning include:

- On-demand availability enables students to complete training conveniently at off-hours or from home.

- Self-pacing for slow or quick learners reduces stress and increases satisfaction.

- Interactivity engages users, pushing them rather than pulling them through training.

- Confidence that refresher or quick reference materials are available reduces burden of responsibility of mastery. 


\section{Case Study}

The presented infrastructure was developed and used in the framework of a European project 'Leonardo Da Vinci', in order to support the development of eenterprising within SMEs in a number of countries in Europe and to strengthen the interaction between education and initial training. These countries include Greece, Italy and Poland and all the corresponding data analysis was provided in the corresponding languages. The SMEs that were involved were activated in the areas of Furniture-Wood-House Furnishings, Mechanics and Shoe-Industry. They were informed on issues of development of innovative methods and training products that aim to strengthen the professional training's contribution with final aim the improvement of enterprising, through the promotion of a new training culture within the SMEs.

\section{Conclusions}

Investment in people is a key differentiator between successful and unsuccessful organizations. In general, E-learning and e-services is a facilitator for organizations to keep up with changes in the global economy. Traditional training methods alone are no longer able to satisfy the demand for the continual updating of employee's skills and knowledge [15,18].

This paper presented an e-activities environment based on a generic and easily adapted architecture. The e-learning tools implemented were based on e-learning standards in order to be used for e-content authoring and management. The system architecture conforms to the principles of interoperability, user-friendliness, interactiveness, and flexibility. The presented environment was adapted to the needs of SMEs in new technologies issues as well as in e-activities such as e-business, ecommerce, e-management and e-advertisement. By training SMEs in the aforementioned issues, they simultaneously become more competitive in the enterprising area, the enterprising increases and consequently, so does the economy.

\section{References}

1. OECD, ICT, E-business AND SMEs, 2004

2. K. Metaxiotis and J. Psarras, E-Government: New Concept, Big Challenge, Success Stories, Electronic Government, an International Journal 1(2), 141-151 (2004).

3. Z. Fang, E-Government in the Digital Era: Concept, Practice, and Development, International Journal of the Computer, The Internet and Management 10(2), 1-22 (2002).

4. A.S. Drigas, L.G. Koukianakis, and S. Domoxoudis, E-Government Structure for EProtocol, E-Application Submission and Internal Organizational and Operational Support, WSEAS TELEINFO 2005 International Conference, Prague, Czech Republic, (2005). 
5. A.S. Drigas and L.G. Koukianakis, E-government Application for Supporting a Network of Distributed Public Administration Units, WSEAS TRANSACTIONS on SYSTEMS, Issue 10 , Volume 3, p. 3336, (2004).

6. A.S. Drigas, Electronic Commerce Framework In Greece, 3rd e-Commerce International Conference for South-Eastern Europe, Sofia, 2000.

7. D. Reuther and G. Chattopadhyay, Critical Factors for Enterprise Resources Planning System Selection and Implementation Projects Within Small to Medium Enterprises, Engineering Management Conference, Proceedings 2004 IEEE International, Vol. 2, pp. 851 855, (2004).

8. P.K.S. Tang and K.F. Tang, Fostering Innovation and Enterprise Creating Enterprising Originals, Engineering Management Conference, Proceedings 2004 IEEE International, 2, pp. $733-736,(2004)$.

9. R.W. Brown and J.F. Odgers, Producing Enterprising Engineers Through Integrated Technology and Business Experiential Learning, Frontiers in Education Conference, Proceedings 1995, 2, pp. 4a4.5 - 4a4.9, (1995).

10. F. Colace, M. DeSanto, and M. Vento, Evaluating On-line Learning Platforms: A Case Study, Proceedings of the 36th Hawaii, International Conference on System Sciences, (IEEE Press, Hawaii, 2003).

11. I, Humar, M. Pustisek, and J. Bester, Developing Dynamic Educational Material with Integrated Mathematical Notation for Web-Based E-Learning System, 33rd ASEE/IEEE Frontiers in Education Conf., Boulder, USA, pp. T3F-19 - T3F - 24, (2003).

12. G. Casadei and M. Magnani, Assessment Strategies of an Intelligent Learning Management System, International Conference on Simulation and Multimedia in Engineering Education, Florida, (2003).

13. N.T. Angehrn and R. Balakrishnan, Integrating 'Context' in E-Learning Systems Design, Proceedings of the IEEE International, Conference on Advanced Learning, Technologies (ICALT 2004), pp. 355-359, (2004).

14. PwC Consulting Introduces 'B2E' - Enterprise Portal Solution to Connect \& Transform Global Organizations. PR Newswire, 2001.

15. M. Harun, Integrating E-Learning into the Workplace, The Internet and Higher Education 4(3-4), 301-310 (2002).

16. R.H. Wild, K.A. Griggs, and T. Downing, A Framework for E-Learning as a Tool for Knowledge Management, Industrial Management and Data Systems 102(7), 371-380 (2002).

17. T. Acton and W. Golden, Training: The Way to Retain Valuable IT Employees? Information Science and Information Technology Education Conference (Ed, Cohen, E.), Ireland, p1-12 (2001).

18. B. Little, Achieving High Performance through E-Learning, Industrial and Commercial Training, 33(6), 203-207 (2001).

19. S. Mann and I. Robertson, Why Should Training Evaluations Evaluate? Journal of European Industrial Training 20(9), 14-20 (1996).

20. S. Graf and B. List, An Evaluation of Open Source E-Learning Platforms Stressing Adaptation Issues, Fifth IEEE International Conference on Advanced Learning Technologies (ICALT'05), pp. 163-165, (2005).

21. V. Fedák, P. Bauer, V. Hajek, H. Weiss, B. Davat, S. Manias, I. Nagy, P. Korondi, R. Miksiewicz, P. van Duijsen, and P. Smékal: Interactive E-Learning in Electrical Engineering, EDPE'03, Int. Conf. on Electrical Drives and Power Electronics. Slovakia, pp. 368-373, (2003).

22. IDC Press Release: The Worldwide Corporate e-Learning Market is on Course to Exceed \$23 Billion by 2004, IDC Says: Non-IT Training Content will Lead the Market by 2004. 
Framingham, MA, (February 27, 2001); http://www.idc.com/getdoc.jhtml?containerId $=$ pr50225

23. D. Ghose, Case Study: HP Fine-Tunes Learning Portal, IT Training (2002).

24. D. O'Donnell and T. Garavan, E-Learning in Irish Organizations? Chartered Institute of Personnel and Development in Ireland, Survey Report, (2003).

25. D. Helic, H. Maurer, and N. Scerbakov, Discussion Forums as Learning Resources in Web-Based Education, Advanced Technology for Learning 1(1), 8-15 (2004).

26. H. Krottmaier, The Future of Digital Libraries, Proceedings of International Conference on Politics and Information Systems: Technologies and Applications, PISTA 2004, I, pp.136$141,(2004)$.

27. Ashenfelter, C. Orley, and R. La Londe, The Economics of Training, The International Library of Critical Writings in Economics 65(1), (1996).

28. J. Stevens and R. Mackay, Training and Competitiveness, National Economic Development Office Policy Issues Series, London, (1999). 